David H. McLeod mB BS FFARACS FFARCSI,

David H.W. Wong MB BS FRCPC,

Richard J. Claridge MD FRCSC, Pamela M. Merrick BSN

\title{
Lateral popliteal sciatic nerve block compared with subcutaneous infiltration for analgesia following foot surgery
}

\begin{abstract}
A new lateral approach to blocking the sciatic nerve in the popliteal fossa is described. In a prospective study, 40 patients scheduled for foot surgery involving osteotomies were allocated randomly into one of two groups following induction of general anaesthesia: group $P S(n=21)$ received a lateral popliteal sciatic nerve block and group $S C(n=19)$ received subcutaneous infiltration of the wound. Both groups received $20 \mathrm{ml}$ bupivacaine $0.5 \%$ plain. The lateral approach to the popliteal sciatic nerve was found to be an effective, quick, and easy to perform, block. Postoperative analgesia in groups PS lasted a median of $18.0 \mathrm{hr}$ and in group SC lasted $6.3 \mathrm{hr}(P<0.05)$. The lateral popliteal sciatic nerve block provided effective analgesia following foot surgery and had a high level of patient satisfaction.
\end{abstract}

Cette communication porte sur une nouvelle approche latérale du bloc sciatique au niveau du creux poplité. Dans une étude prospective, 40 patients programmés pour une chirurgie du pied avec ostéotomie sont repartis au hasard entre deux groupes après linduction de l'anesthésie générale: le groupe PS ( $n=$ 21) reçoit un bloc du sciatique poplité externe et le groupe $S C(n=19)$ une infiltration sous-cutanée de la plaie. Aux deux groupes, on administre de la bupivacaïne $20 \mathrm{ml}$ sans épinéphrine. L'approche latérale du nerf poplité est jugée efficace, rapide et facile à exécuter. L'analgésie postopératoire dans le groupe PS dur 18,0 h (médiane) et dans le groupe SC 6,3 $h(P<0,05)$. Le bloc du sciatique poplité externe procure

\section{Key words}

ANAESTHETIC TECHNIQUES, REGIONAL: sciatic nerve block, subcutaneous infiltration;

SURGERY: orthopaedic.

From the Department of Anaesthesia, Faculty of Medicine, University of British Columbia, Vancouver, British Columbia. Address correspondence to: Dr. David Wong, Department of Anaesthesia, Vancouver General Hospital, 855 West 12th Avenue, Vancouver, BC, V5Z $1 \mathrm{M} 9$.

Accepted for publication 1st May, 1994. une analgésie efficace après une chirurgie du pied avec un degré de satisfaction élevé chez le patient.

Surgery of the foot is often carried out in day surgical units. The postoperative pain that follows can be moderate to severe and difficult to control with oral anaglesics. Popliteal sciatic nerve block is a recognised way of providing analgesia and anaesthesia of the lower limb, ' and the expected duration of analgesia is 14 to $18 \mathrm{hr}$ using bupivacaine. ${ }^{2}$ Popliteal sciatic nerve block has the advantage over more proximal sciatic blocks of preserving hamstring function and allowing early ambulation with crutches. A recently described lateral approach to the popliteal sciatic nerve has the further advantage of being inserted with the patient supine rather than prone. ${ }^{3}$ This paper describes the lateral approach to the popliteal sciatic nerve and compares its postoperative analgesic effect with that of subcutaneous wound infiltration with local anaesthetic.

\section{Anatomical perspective}

The popliteal fossa is a diamond-shaped area located behind the knee, bound inferiorly by the medial and lateral heads of gastrocnemius, superio-laterally by biceps femoris, and superior-medially by the tendons of semitendinosus and semimembranosus. The sciatic nerve is formed from spinal cord segments $\mathrm{L}_{4}$ through to $\mathrm{S}_{5}$. All innervation below the knee is from the sciatic nerve except for the cutaneous area antero-medial on the leg down to a variable area of the medial aspect of the foot, which is supplied by the saphenous nerve, the terminal branch of the femoral nerve.

The sciatic nerve is actually two nerves contained within a common connective tissue sheath, the larger tibial division located medially and the common peroneal located laterally. At the apex of the popliteal fossa the sciatic nerve terminates into its component nerves where they are held in close proximity for an additional 1 to $3 \mathrm{~cm}$ by the surrounding connective tissue sheath so that 
lateral divergence of the common peroneal nerve in its course through the popliteal fossa is gradual. The tibial nerve continues in the same direction as the sciatic and is parallel to and $1.0 \mathrm{~cm}$ lateral to the midline of the popliteal fossa. ${ }^{4}$ At the apex of the fossa, the sciatic nerve lies deep to the biceps femoris muscle but in close proximity to the biceps femoris tendon along the muscle's posterior border (Figure 1).

\section{Methods}

After ethics committee approval and informed consent, 40 ASA 1 and 2 female patients aged 18 to $70 \mathrm{yr}$ were studied in a single blind, prospective manner. Patients were ambulatory cases and had foot surgery involving osteotomies. Patients suffering neurological or neuromuscular disease, sciatica, infection at the proposed block site, a history of hypersensitivity to amide local anaesthetics or those in whom a laryngeal mask was deemed to be contraindicated were excluded from the study. Standardised general anaesthesia consisted of induction with propofol 2 to $3 \mathrm{mg} \cdot \mathrm{kg}^{-1}$, fentanyl $1-2 \mathrm{mg} \cdot \mathrm{kg}^{-1}$, and spontaneous respiration with $\mathrm{N}_{2} \mathrm{O} / \mathrm{O}_{2}$ / isoflurane via a laryngeal mask. Patients were randomly assigned to receive either a lateral popliteal sciatic nerve block (group PS) or subcutaneous infiltration of the wound (group SC). In both groups the local anaesthetic consisted of $20 \mathrm{ml}$ bupivacaine $0.5 \%$ plain. Patients in group PS had all $20 \mathrm{ml}$ of local anaesthetic injected immediately after induction, but prior to skin incision. Those in group SC had $10 \mathrm{ml}$ of local anaesthetic infiltrated immediately after induction, with the remaining $10 \mathrm{ml}$ infiltrated at the end of surgery prior to wound closure.

All lateral popliteal sciatic blocks were performed by one investigator (DM) and wounds were infiltrated by the attending foot surgeon (RC).

\section{The lateral popliteal sciatic nerve block}

With the patient supine and lower leg elevated on a pillow the biceps femoris tendon on the lateral aspect of the lower thigh was identified at a point where it meets the popliteal fossa skin crease. The tendon was traced proximally for $5 \mathrm{~cm}$. A 22-gauge, $7.3 \mathrm{~cm}$, insulated, block needle was inserted immediately anterior to the tendon in a horizontal plane with slight cephalad angulation (Figure 2). A low output peripheral nerve stimulator produced plantar flexion with minimal current from excitation of the more crucial posterior tibial nerve. Correct location of the needle was confirmed by abolition of foot twitching immediately following a $1 \mathrm{ml}$ test dose of local anaesthetic.

Postoperative pain assessments were completed by post-anaesthetic recovery (PAR) nurses at 0,1 , and 2 $\mathrm{hr}$ and at discharge. Nurses were unaware of which group

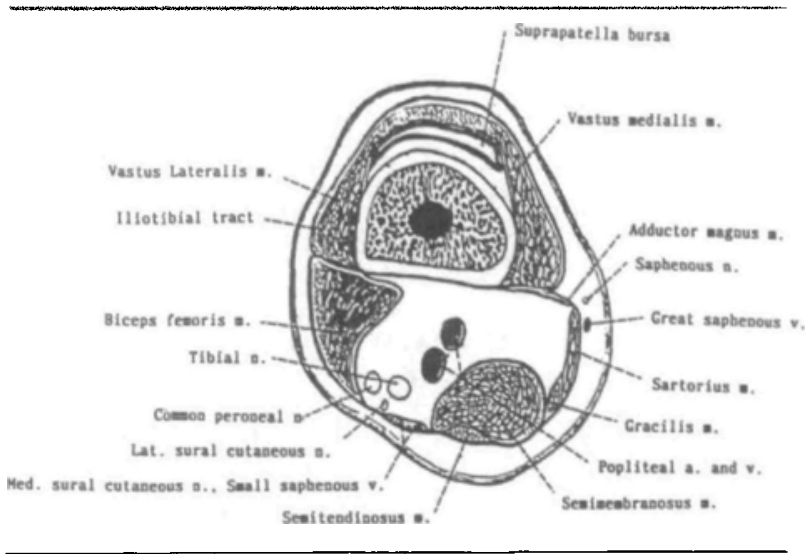

FIGURE 1 Section of distal left thigh through suprapatellar bursa, viewed from above.

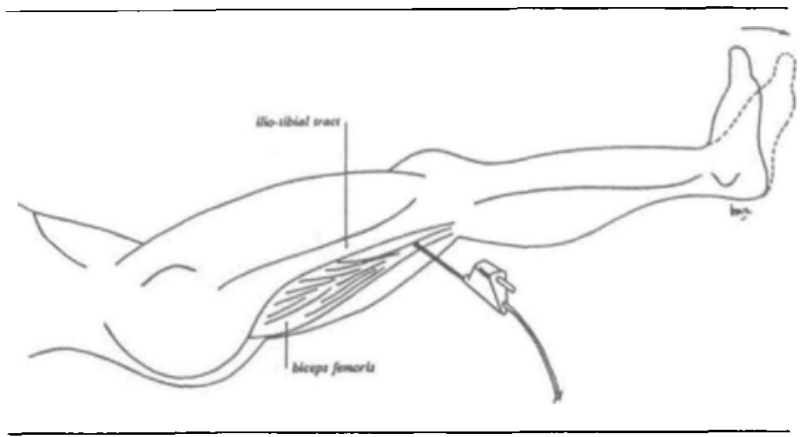

FIGURE 2 Needle placement for lateral sciatic nerve block.

the patients were in. Patients completed a visual analogue scale (VAS) by placing a mark on a $10-\mathrm{cm}$ vertical line. A verbal rating scale (VRS) was also used whereby patients rated their discomfort as "none, mild, moderate, severe, or very severe." Postoperative analgesia consisted of morphine $i v$ if required, followed by Tylenol \#3 to two tablets four to six hourly (each Tylenol \#3 tablet contains acetaminophen $300 \mathrm{mg}$, caffeine $15 \mathrm{mg}$, and codeine phosphate $30 \mathrm{mg}$ ). A telephone follow-up was done the evening after surgery by a blinded interviewer (DW). Patients were asked to rate their pain at home, note at what time their foot began to hurt, questioned about side effects, rated their satisfaction with postoperative relief and invited to make any comments (Table I). Continuous demographic variables and VAS scores were analysed using Mann-Whitney tests. The VRS pain scores were analysed with a Chi-square or Fisher's exact tests with Bonferroni's correction applied. The rest of the variables were tested for differences between groups with uncorrected Chi-square or Fisher's exact tests. Some Chisquare categories were combined when cell sizes were too small. $P<0.05$ was considered significant except where Bonferroni's correction was used. 
TABLE I Telephone questionnaire. (Patients telephoned on the evening of the day following surgery)

1 How much pain have you had on the day of surgery? Answer: "none, mild, moderate, severe, very severe."

2 What time did your foot begin to feel uncomfortable?

3 Have you suffered any side effects since leaving the day surgical centre?

4 How would you rate your over-all satisfaction with pain relief? Answer: "completely satisfied, satisfied with reservations, dissatisfied."

5 Would you like to make any comments?

TABLE II Patient data. Values expressed as median (range) or counts

\begin{tabular}{lll}
\hline & $\begin{array}{l}\text { Group PS } \\
(n=21)\end{array}$ & $\begin{array}{l}\text { Group } S C \\
(n=19)\end{array}$ \\
\hline Age (yr) & $42(22-66)$ & $50(18-70)$ \\
Weight (kg) & $58(42-88)$ & $65(43-88)$ \\
Operation & & \\
- MTP arthrodesis/resection & 10 & 10 \\
- Chevron/cheilectomy & 6 & 7 \\
- Other & 5 & 2 \\
Duration of anaesthesia (min) & $90(50-130)$ & $90(45-120)$ \\
\hline
\end{tabular}

\section{Results}

We studied 40 female patients and all were successfully followed up. There were no differences between the groups in number, age, weight, operation and length of anaesthesia (Table II). In the PS group the mean time taken for sciatic block insertion was $4.5 \mathrm{~min}$ (SD 1.1). The mean needle depth for block was $44.2 \mathrm{~mm}$ (SD 7.5). There were no differences between the groups in the PAR with respect to VAS (Table III), morphine or Tylenol used, antiemetics received or side effects encountered. There were no differences found between the groups in the PAR with respect to VRS except at the baseline assessment where more patients in PS complained of "moderate" or "severe" pain (42\%) than in group SC (5\%) (Table IV), $P<0.05$. The median analgesic time of 1082 min (Range 375-1930) in group PS was longer than in group SC, 373 min (Range 185-420), $P<0.05$. Group PS had less "severe" or "very severe" pain at home (14\%) compared with group SC (58\%), $P<0.05$. There were more patients in group PS who reported being satisfied with their postoperative analgesia (95\%) than in group SC (58\%), $P<0.05$ : $5 \%$ of group PS were completely dissatisfied with their over-all analgesia compared with $42 \%$ of group SC, $P<0.05$ (Table V).

\section{Discussion}

This study indicates that this new lateral approach to the sciatic nerve in the popliteal fossa can be used to
TABLE III Mean VAS scores in PAR (0- $10 \mathrm{~cm} \mathrm{scale)}$

\begin{tabular}{llll}
\hline & $P S$ & $S C$ & $P$ \\
\hline Baseline & 0.6 & 0.1 & 0.3209 \\
One hr & 1.0 & 1.1 & 0.8378 \\
Two hr & 1.0 & 0.5 & 0.5728 \\
Discharge & 0.3 & 0.6 & 0.9267 \\
\hline
\end{tabular}

TABLE IV VRS in PAR (\% with moderate to severe pain)

\begin{tabular}{llrl}
\hline & $P S$ & $S C$ & $P$ \\
\hline Baseline & 42 & 5 & $0.0076^{*}$ \\
One hr & 25 & 33 & 0.5717 \\
Two hr & 20 & 0 & 0.2885 \\
Discharge & 24 & 20 & 1.0 \\
\hline
\end{tabular}

Statistical significance * $P<0.0125$ (Bonferroni's correction)

TABLE V Postoperative pain assessments. Values expressed as counts and percentages. Duration of analgesia expressed as medians with ranges

\begin{tabular}{lcc}
\hline & $P S$ & $S C$ \\
\hline Pain at home & & \\
- none, mild, moderate & $18 / 21(86 \%)^{*}$ & $7 / 19(39 \%)$ \\
- severe, very severe & $3 / 21(14 \%)^{*}$ & $11 / 19(58 \%)$ \\
Duration analgesia (min) & $1082(\mathrm{R} \mathrm{375-1930)*}$ & $373(\mathrm{R} 185-420)$ \\
Satisfaction with analgesia & & \\
- Satisfied & $17 / 21(81 \%)^{*}$ & $7 / 19(37 \%)$ \\
- Satisfied with reservations & $3 / 21(14 \%)$ & $4 / 19(21 \%)$ \\
- Dissatisfied & $1 / 21(5 \%)$ & $8 / 19(42 \%)$ \\
\hline
\end{tabular}

Statistical significance $* P<0.05$.

provide effective and long-lasting analgesia following foot surgery involving osteotomies.

Insertion of the lateral popliteal sciatic nerve block was quick and accomplished in a mean time of $4.5 \mathrm{~min}$. Nerve localisation as evidenced by plantar flexion in response to minimal current from a low-output peripheral stimulator was easily accomplished in all but one of the PS group. The mean needle depth at time of maximal twitch was $4.4 \mathrm{~cm}$.

Whilst $42 \%$ of patients in group PS complained of moderate or severe pain using the VRS, most did not appear clinically to be suffering severe pain. These patients characteristically complained of moderate or severe pain when asked but without exhibiting any accompanying signs such as restlessness, tearfulness or grimacing that are often observed in patients suffering severe pain. This pain was, in all but one case, easily controlled with modest doses of intravenous morphine, following which patients remained comfortable until the sciatic blocks resolved some $18 \mathrm{hr}$ later. We suspect this initial pain was 
due to the surgery encroaching upon the territory of the saphenous nerve which was not blocked. In group PS 17 of the 21 patients had vertical incisions on the dorsum of the foot, overlying the hallux and first metatarsal. As the saphenous nerve is sensory to the skin, the derived pain was only from the skin incision and was easily managed with small doses of opioids or oral analgesics. In support of this contention, a number of patients localised their pain superficially, on the anteromedial aspect of the foot. We would therefore recommend that the lateral popliteal sciatic nerve block be combined with either a saphenous nerve block or subcutaneous infiltration of the wound if surgery on the hallux or medial aspect of the foot or ankle is to be undertaken.

Although subcutaneous infiltration afforded comparable analgesia in the early postoperative phase, it lasted a median of only $373 \mathrm{~min}(6.2 \mathrm{hr})$ and, after resolution, left patients in considerable pain. In group SC $42 \%$ of patients were dissatisfied with their postoperative analgesia and half sought alternative medical follow-up on the night or day following surgery due to intolerable postoperative pain uncontrolled by strong oral analgesics. In comparison, the PS group sustained long lasting analgesia of $1082 \mathrm{~min}(18.0 \mathrm{hr}$ ) median duration. All but one patients in this group were satisfied with their postoperative pain management. None of this group sought alternative medical follow-up.

In summary the lateral approach to the popliteal sciatic nerve is an effective, quick, and easy to perform block. Using $20 \mathrm{ml}$ bupivacaine $0.5 \%$ plain, analgesia lasts a median $18.0 \mathrm{hr}$ compared with subcutaneous local anaesthetic infiltration which lasts $6.2 \mathrm{hr}$. It provides effective analgesia following hallux valgus correction and other foot procedures and has a high level of patient satisfaction.

\section{Acknowledgements}

The authors thank the staff of the Surgical Day Care Centre at the Vancouver General Hospital for their cooperation during this study.

\section{References}

1 Labat G. Regional Anesthesia. Philadelphia: W.B. Saunders Company 1922, 291-3.

2 Coventry DM, Todd JG. Alkalinisation of bupivacaine for sciatic nerve blockade. Anaesthesia 1989; 44: 467-70.

3 Collum $C R$, Courtney $P G$. Sciatic nerve blockade by a lateral approach to the popliteal fossa. Anaesth Intensive Care 1993; 21: A236-7.

4 Rorie DK, Byer DE, Nelson DO, Sittipong R, Johnson $K A$. Assessment of block of the sciatic nerve in the popliteal fossa. Anesth Analg 1980; 59: 371-6. 